https://doi.org/10.48009/1_iis_2009_62-68

\title{
THE IMPACT OF COMPUTER SCREEN RESOLUTION SETTING ON STUDENT COMPUTER-BASED HANDS-ON TASK PERFORMANCE IN AN INTRODUCTORY INFORMATION SYSTEMS COURSE
}

\author{
Allen D. Truell, Ball State University, atruell@bsu.edu \\ Melody W. Alexander, Ball State University, malexand@bsu.edu \\ Jensen J. Zhao, Ball State University, jzhao@ bsu.edu
}

\begin{abstract}
Over the past several decades, considerable research has been completed exploring the possible influence various computer-based testing formats could have on student performance. Indeed, a simple search of the ERIC database using the descriptor "computer assisted testing" dated 1988 through 2008 returned over 1,800 citations. The thrust of many early studies was on assessing the consistency of student performance on computer-based and paper-andpencil versions of the same test. Most recently researchers have expressed the need for studies exploring the potential impact computer-based test interface configurations on student performance. Thus, the purpose of this posttest only experimental control group design study was to determine if there was a significant difference in student hands-on task performance based on computer screen resolution setting. Study results indicate that student hands-on task performance is not significantly impacted by computer screen resolution setting. These same results were found when the variable gender was included in the analysis.
\end{abstract}

Keywords: Computer-based testing; hands-on performance tasks; computer screen resolution setting

\section{INTRODUCTION}

Computer use has had a profound impact on humans for more than five decades [5]. Specific to educational settings, both instructors and the students they teach have been impacted by the increased use of computers for testing purposes. One reason for this trend toward using computer-based testing is its many reported benefits for both instructors and students [10]. These benefits have been reported to include ease of administration, immediate feedback on performance to students, reduced test production costs, and reduced scoring time [16]. Even with the stated benefits of computer-based testing, concern has been expressed about the potential impact of computer-based test interface configurations on

Volume X, No. 1, 2009 student performance $[3,4,14,17,18,19,20]$. Thus, researchers have begun examining the potential impact of various computer interface configurations on student performance $[3,4,18,19,20]$. What computer users see and interact with is the interface [14].

Several studies exploring the impact of computerbased test interface configurations on student performance can be found in the literature. One study comparing student performance involving two computer-based test interface configurations and paper-and-pencil test formats, reported no significant difference in student performance. Specifically, there was no significant difference in student scores or test completion times between the two computer-based test configurations. When the variable gender was added to the analysis, a significant difference was noted in student performance. Specifically, female participants achieved higher test scores than did male participants. This significant difference was not considered to be of a practical difference as its associated effect size was small. The researcher noted that additional study of various computer-based test interface configurations was warranted [18].

In another study, the impact of instructor settable computer interface configurations on student computer-based test performance was explored. Specifically, scores and test completion times, on three instructor settable item exposure interface configurations of a computer-based testing system. Study results indicated that there was no significant difference in student scores or test completion times based on the three instructor settable item exposure interface configurations [19]. Researchers in a similar study, assessed student performance on three instructor controlled computer-based test configurations: all-at-once, scroll; one-at-a-time, revisit; and one-at-a-time, no revisit. The results of this study were mixed. Specifically, their findings indicated that there was no significant difference in student scores across the three instructor controllable computer-based test interface configurations. There 
was a significant difference in test completion times across the three instructor controllable test configurations. Specifically, students completed the instructor controllable computer-based test configuration of one-at-a-time, no revisit the fastest. The researchers postulated that this completion time difference was a result of the flexibility associated with the all-at-once, scroll and one-at-a-time, revisit computer-based test interface configurations. They explained that while there was a statistically significant difference in test completion times, it was likely of little practical difference [3].

In a related study, the impact of screen resolution setting on student verbal and mathematical computerbased test scores was assessed. Study findings were mixed. Expressly, no significant difference in student scores was found on the math portion of the computer-based test based on screen resolution setting. A significant difference was found in student scores on the verbal portion of the computer-based test based on screen resolution setting. Students completing the verbal portion of the test at higher computer screen resolution settings achieved higher average scores than did students completing the verbal portion of the test on the lower computer screen resolution setting. The researchers stated that differences in screen resolution settings students might encounter with computer-based testing may impact on student computer-based test scores and that more research on the topic is needed [4].

In another study, the impact of screen resolution setting on student computer-based test performance was explored. Specifically, that study sought to determine if student scores and test completion times differed significantly on a 50-item true/false test based on computer screen resolution setting. Computer screen resolution settings in that study were $600 \times 800$ and $1280 \times 1024$, respectively. No significance difference in student computer-based true/false test scores or test completion times based on screen resolution setting was found. No significant difference in student computer-based true/false test scores or test completion times based on screen resolution setting was found when the variable gender was included in the analysis. The researchers suggested that additional studies assessing student computer-based test performance and screen resolution settings were necessary [20].

A related computer-based testing study reported students had difficulty reading from a computer screen. It was noted that this reading difficulty could influence student performance on computer-based

Volume X, No. 1, 2009 tests. As such, it was recommended that student performance on computer-based tests be carefully monitored to confirm, fair and constant assessments [17]. In addition, the computer-based testing interface has been reported to be extremely important because of its potential threat to construct validity. A difficult to use computer-based test interface could contribute to construct-irrelevant variance. Construct-irrelevant variance makes any test results questionable [8]. Other researchers have suggested that the computer-based testing interface is a important measurement concern and that understanding potential differences in student performance is critical $[12,14]$. Another researcher noted that lower resolutions may require test takers to spend more time locating information because more scrolling and visual sweeps is needed to process shorter text lines. Further, lower resolutions may increase processing difficulty if critical information is split across screens [1].

Other studies have assessed the impact of computer interface configurations on users in related areas [1, $6,11]$. One study assessed perceptions of various fonts for legibility, ease of reading, and font sharpness and attraction at the 12- and 14-point sizes on computer screens by gender. Results of this study were mixed. Specifically, males perceived the 14point size as easier to read and to have a sharper focus. Female perceived little difference in readability and focus based on font size, 12- or 14point. Both males and females reported a preference for 14-point sans serif fonts [2]. In a similar study, the effects of age and handheld computer font size on reading text of font sizes between 2 and 16 point on text reading. Results of this study showed little difference in reading performance above 6 point. Participant preferences for font sizes in the middle range were noted. As such, it was recommended that interface designers consider the font range of 8 to 12 point to meet the needs of most users [6]. Results of a similar study exploring the readability of newspaper headlines on a computer screen based on typeface, point size, screen resolution, and monitor size found point size to be a significant factor [11].

\section{NEED FOR THE STUDY}

Considerable research regarding computer-based testing in general has been completed. A significant portion of this research has explored the consistency of paper-and-pencil tests adapted for computer-based delivery. Given the potential impact of the interface, numerous researchers have called for additional studies assessing this component of computer-based 
testing $[4,13,15,17]$. Another researcher questioned whether computer-based test interface designs enhanced or deterred student performance. This same researcher noted that regardless of assessment purpose, computer-based tests must be fair measurement instruments and that research can assist with the confirmation process [13]. Thus, this study builds upon the recommendations of earlier researchers in that more study is needed regarding the potential impact of interface configurations on student computer-based test performance. In addition, this study appears to be the first to assess the potential impact of interface configurations with hands-on performance tasks.

\section{PURPOSE}

The purpose of this posttest only experimental control group design study was to determine if there was a significant difference in student hands-on task performance based on computer screen resolution setting. Specifically, answers to the following four research questions were sought.

1. Is there a significant difference in student handson performance task scores based on computer screen resolution setting?

Table 1

Illustration of the Posttest Only Experimental Control Group Design

\begin{tabular}{|c|c|c|}
\hline Assignment & Treatment & $\begin{array}{c}\text { Scores/Hands-On Performance } \\
\text { Task Completion Times }\end{array}$ \\
\hline $\mathrm{R}$ & $\mathrm{X} 1$ & YES (O) \\
\hline $\mathrm{R}$ & $\mathrm{X} 2$ & YES (O) \\
\hline
\end{tabular}

$\mathrm{R}=$ Random assignment to groups; $\mathrm{X} 1$ = Unusual treatment (computer screen resolution setting, $600 \mathrm{X}$ 800); X2 = Control treatment (computer screen resolution setting, 1280 X 1024); O = Scores/Hands-On Performance Task Completion Times.

\section{Study Participants}

Study participants were those students $(n=64)$ enrolled in two sections of an introductory information systems course. Of these 64 participants, $29(45 \%)$ were female and $35(55 \%)$ were male. Data were collected during the fall 2008 semester at a public, Midwestern university. Participants received a small IRB approved "extra credit" incentive for partaking in the study.

Data collection procedures
2. Is there a significant difference in student handson performance task completion times based on computer screen resolution setting?

3. Is there a significant difference in student task scores based on computer screen resolution setting by gender?

4. Is there a significant difference in student handson performance task completion times based on computer screen resolution setting by gender?

\section{METHODOLOGY}

The research design, study participants, data collection procedures, and data analysis are presented next.

\section{Research design}

The posttest only experimental control group design provided the study framework. This experimental design was used in this study because it controls for most sources of internal and external invalidity [9]. The posttest only experimental control group design used for this study is presented in Table 1. 
Participants were knowledgeable of this software as it was routinely used as part of class for both assessment and training purposes. Participants used Gateway® desktop computers model E-2600S and Gateway® 17-inch LCD flat panel display monitors model FPD1765 for both normal classroom activities and for study completion. All other computer interface configurations were held consistent during the study.

\section{Data analysis}

Research questions one and two sought to determine if significant differences existed in participant handson performance task scores and task completion times based on computer screen resolution setting. Research questions three and four sought to determine if significant differences existed in participant hands-on performance task scores and task completion times based on computer screen resolution setting by gender. To determine answers the four research questions, $2 \mathrm{X} 2$ factorial ANOVAs with main and interaction effects were calculated. The descriptive statistics means and standard deviations were used show the data used in the ANOVA analyzes. Tests of statistical significance were set at alpha $(\alpha)=.05$. To present a measure of effect size, the eta squared $\left(\eta^{2}\right)$ values associated with the ANOVA analyses are reported [7].

\section{RESULTS}

Results for each of the four research questions follow.

\section{Research Question One}

Research question one sought to determine if there was a significant difference in participant hands-on performance task scores based on computer screen resolution setting. ANOVA analysis, $\underline{F}(1,60)=<$ $1.795, \underline{\mathrm{p}}=0.185$ indicated that there was no significant difference in participant hands-on performance task scores based on computer screen resolution setting. Table 2 presents the ANOVA analysis for research question one. The descriptive statistics for this analysis appear in Table 4.

\section{Research Question Two}

Research question two sought to determine if there was a significant difference in participant hands-on performance task completion times based on computer screen resolution setting. ANOVA analysis, $\underline{F}(1,60)=0.715, \underline{p}=0.401$ indicated that there was no significant difference in participant hands-on performance task completion times based on computer screen resolution setting. Table 3 presents the ANOVA analysis for research question two. The descriptive statistics for this analysis appear in Table 4.

\section{Research Question Three}

Research question three sought to determine if there was a significant difference in participant hands-on performance task scores based on computer screen resolution setting by gender. ANOVA analysis, $\underline{F}(1$, $60)=3.581, p=0.063$ indicated that there was no significant difference in participant hands-on performance task scores based on computer screen resolution setting by gender. Table 2 presents the ANOVA analysis for research question three. The descriptive statistics for this analysis appear in Table 4.

\section{Research Question Four}

Research question four sought to determine if there was a significant difference in participant hands-on task performance task completion times based on computer screen resolution by gender. ANOVA analysis, $\underline{F}(1,60)=0.471, \underline{p}=0.495$ indicated that there was no significant difference in participant hands-on performance task completion times based on computer screen resolution setting by gender. Table 3 presents the ANOVA analysis for research question four. The descriptive statistics for this analysis appear in Table 4.

Table 2

ANOVA for Performance Task Score by Gender and Computer Screen Resolution Setting

\begin{tabular}{lcrrrrr}
\hline Effect & Type III SS & df & Mean Square & F & p & \\
Dependent Variable (Score) & & & & & $\eta^{2}$ \\
Computer Screen & & & & & \\
Resolution Setting & 6.680 & 1 & 6.680 & 1.795 & .185 \\
Gender & .012 & 1 & .012 & .003 & .956 & $<.001$
\end{tabular}

Computer Screen Resolution 
The Impact of Computer Screen Resolution Setting on Student Computer-based Hands-on Task Performance in an Introductory Information Systems Course

\begin{tabular}{|c|c|c|c|c|c|c|}
\hline Setting X Gender & 13.332 & 1 & 13.332 & 3.581 & .063 & .05 \\
\hline Error & 223.348 & 60 & 3.722 & & & \\
\hline Total & 241.750 & & & & & \\
\hline
\end{tabular}

\section{CONCLUSION AND DISCUSSION}

This 64 participant posttest only control group experimental study was completed at one public university located in the Midwestern United States. In addition, the hardware and software used in this study was limited to what was available in the classroom where the study was conducted. As such, the study conclusion is put forward with these caveats noted. Based on the results of this study, no significant difference in student hands-on task performance based on computer screen resolution setting, it is concluded that instructors can push forward with their use of hands-on performance tasks reasonably confident that student achievement will not be significantly impacted by computer screen resolution setting. This conclusion is supported by data in Tables 2, 3, and 4.

Table 3

ANOVA for Performance Task Completion Time by Gender and Computer Screen Resolution Setting

\begin{tabular}{lrrrcrl}
\hline Effect & Type III SS & df & Mean Square & F & p & $\eta 2$ \\
$\begin{array}{l}\text { Dependent Variable (Time) } \\
\text { Computer Screen }\end{array}$ & & & & & & \\
$\begin{array}{l}\text { Resolution Setting } \\
\text { Gender }\end{array}$ & 33824.346 & 1 & 33824.346 & .715 & .401 & .012 \\
$\begin{array}{l}\text { Computer Screen Resolution } \\
\text { Setting X Gender }\end{array}$ & 55347.500 & 1 & 55347.500 & 1.170 & .284 & .019 \\
Error & 22267.346 & 1 & 22267.346 & .471 & .495 & .008 \\
Total & 2837562.627 & 60 & 47292.710 & & & \\
\hline
\end{tabular}

Results of this study are congruent with several researchers exploring the impact of various computer interface configurations on student computer-based performance $[18,19,20]$. Specifically, the results of this study are consistent with the research results of these earlier studies in that various computer interface configurations examined did not significantly impact student computer-based test performance. The results of this study are partly consistent with the earlier work of other researchers $[3,4]$.

Table 4

Descriptive Statistics for the Data in the Analysis

\begin{tabular}{|c|c|c|c|c|c|}
\hline & \multirow[b]{2}{*}{ Frequency } & \multicolumn{2}{|c|}{ Test Score } & \multicolumn{2}{|c|}{ Test Completion Time } \\
\hline & & Mean & $\begin{array}{l}\text { Standard } \\
\text { Deviation }\end{array}$ & Mean & $\begin{array}{l}\text { Standard } \\
\text { Deviation }\end{array}$ \\
\hline \multicolumn{6}{|l|}{ Screen Resolution } \\
\hline Low (=Large) & 32 & 16.97 & 1.787 & 691.91. & 224.323 \\
\hline High $(=$ Small $)$ & 32 & 16.41 & 2.108 & 732.75 & 209.055 \\
\hline \multicolumn{6}{|l|}{ Gender } \\
\hline Female & 29 & 16.69 & 2.301 & 680.86 & 198.453 \\
\hline Male & 35 & 16.69 & 1.659 & 738.40 & 229.207 \\
\hline Total & 64 & 16.69 & 1.959 & 712.33 & 216.078 \\
\hline
\end{tabular}


Results of this study are similar to the results found by these researchers [3] in that student test scores were not significantly different based on computer interface configuration; by contrast, results of this study are dissimilar with the work of these researchers [3] in that the current study found no significant differences in student test completion time while in their [3] study significant differences were found in student test completion time based on computer interface configuration. They noted that the statistical significance in student computer-based test completion time for the various interface configurations was likely of little practical significance. The results of the current study are partly consistent with the earlier work of other researchers [4]. Specifically, they reported mixed results. These researchers found no significant difference in student scores on the math portion of a computer-based test; in contrast, the researchers found a significant difference in student scores on the verbal portion of the computer-based test. Specifically, students completing the verbal test portion with a higher computer screen resolution achieved higher average scores than did those students completing the verbal portion of the test on the low computer screen resolution setting.

\section{ADDITIONAL RESEARCH RECOMMENDATIONS}

Based on the results of this study and a review of the literature, the following additional research recommendations are offered.

1. Since relatively few studies have examined the possible impact interface configurations may have on computer-based test performance, additional study is needed. Additional research would build a much needed literature base concerning computer-based testing and the potential impact various computer interface configurations might have on student performance.

2. Participants in this study completed hands-on performance tasks on a commercially available software program assessing performance on Word component of the Microsoft Office Suite. As such, it is recommended that other components of the Microsoft Office Suite be explored for potential student performance differences (e.g., Access, Excel, and PowerPoint).
3. Participants in this study completed hands-on performance tasks using one commercially available software assessment and training system. It is recommended that this study be replicated using other commercially available software assessment and training systems. Such studies would provide further insight into the potential impact different commercially available assessment and training programs might have on student hands-on performance tasks.

\section{REFERENCES}

1. Bennett, R. E. (2003). Online assessment and the comparability of score meaning (ETS RM03-05). Princeton, NJ: ETS.

2. Bernard, M. L., Chaparro, B. S., Mills, M. M., \& Halcomb, C. G. (2003). Comparing the effects of text size and format on the readability of computer-displayed Times New Roman and Arial text. International Journal of HumanComputer Studies, 59, 823-835.

3. Bodmann, S. M., \& Robinson, D. H. (2004). Speed and performance differences among computer-based and paper-pencil tests. Journal of Educational Computing Research, 31(1), 5160.

4. Bridgeman, B., Lennon, M. L., \& Jackenthal, A. (2003). Effects of screen size, screen resolution, and display rate on computer-based test performance. Applied Measurement in Education, 16(3), 191-205.

5. Chalmers, P. A. (2000). User interface improvements in computer-assisted instruction, the challenge. Computers in Human Behavior, 16(5), 507-517.

6. Darroch, I., Goodman, J., Brewster, S., \& Gray, P. (2005). The effect of age and font size on reading text on handheld computers. INTERACT, 3585, 253-226.

7. Gravetter, F. J., \& Wallnau, L. B. (2007). Statistics for the behavioral sciences (7th ed.). Belmont, CA: Thomson Higher Education.

8. Fulcher, G. (2003). Interface design in computer-based language testing. Language Testing, 20(4), 384-408.

9. Gay, L. R., Mills, G. E. \& Airasian, P. (2006). Educational research: Competencies for analysis and application (8th ed.). Upper Saddle River, NJ: Prentice-Hall.

10. Goldberg, A. L., \& Pedulla, J. J. (2002). Performance differences according to test mode and computer familiarity on a practice graduate record exam. Educational and Psychological Measurement, 62(6), 1053-1067. 
The Impact of Computer Screen Resolution Setting on Student Computer-based Hands-on Task Performance in an Introductory Information Systems Course

11. Kingery, D., \& Furuta, R. (1997). Skimming electronic newspaper headlines: A study of typeface, point size, screen resolution, and monitor size. Information Processing \& Management, 33(5), 685-696.

12. Leeson, H. V. (2006). The mode effect: A literature review of human and technological issues in computerized testing. International Journal of Testing, 6(1), 1-24.

13. Luecht, R. M. (2001). Challenges of web-based assessment. Paper presented at the Annual Meeting of the National Council on Measurement in Education, Seattle, WA. (ERIC Document Reproduction Service No. ED458294)

14. Parshall, C. G., Spray, J. A., Kalohn, J. C., \& Davey, T. (2002). Practical consideration in computer-based testing. New York, NY: Springer.

15. Pommerich, M. (2002). The effects of administration mode on test performance and score precision, and some factors contributing to mode differences. Paper presented at the Annual meeting of the National Council on Measurement in Education, New Orleans, LA.
(ERIC Document Reproduction Service No. ED464934)

16. Pomplun, M., Frey, S., \& Becker, D. F. (2002). The score equivalence of paper-and-pencil and computerized versions of a speeded test of reading comprehension. Educational and Psychological Measurement, 62(2), 337-354.

17. Ricketts, C., \& Wilks, S. J. (2002). Improving student performance through computer-based assessment: Insights from recent research. Assessment \& Evaluation in Higher Education, 27(5), 475-479.

18. Truell, A. D. (2005). Comparing student performance on two computer-based user interfaces and paper-and-pencil test formats. NABTE Review, 32, 29-35.

19. Truell, A. D., Zhao, J. J., \& Alexander, M. W. (2005). The impact of settable test item exposure control interface format on postsecondary business student test performance. Journal of Career and Technical Education, 22(1), 31-41.

20. Truell, A. D., Zhao, J. J., \& Alexander, M. W. (in press). The impact of screen resolution setting on business student computer-based test performance.

NABTE Review 
